\title{
Managing Spares Inventory Through Life Time Value Assessment
}

\author{
Mohita Gangwar Sharma \\ Operations Management Area, FORE School of Management, New Delhi, India \\ Email: mohita@fsm.ac.in (Corresponding Author)
}

\author{
Kashi N. Singh \\ Operations Management Area, Indian Institute of Management, Lucknow 226 013, India \\ E-mail: kns@iiml.ac.in
}

\begin{abstract}
Spare Parts Management in capital equipment intensive industries is a critical differentiating factor. As we work in a resource crunch environment, we have changed the vantage point for spares management system in this study. Determining the value and usefulness of the spare parts and understanding which spare part is more valuable should guide us in committing resource. Instead of looking from the vantage point of the equipment where the spare is used this spare considers spare part as an investment based on its value. Real Option Analysis has been identified in the literature as a quantitative means to evaluate the flexibility inherent in the decision making process. By adopting a real options framework we develop a model that incorporates the demand uncertainty and the financial implications involved. The value derived in terms of asset utilization determines the viability of this investment. Thus, the concept of 'Spares Life Time Value' has been proposed based on an analogy from 'Customer life time value'. In this model the contribution of spare part reduces to an argument which can be used for strategic insights and decision making. The concept has been illustrated through a case study on the issue of spare resource allocation.
\end{abstract}

Keywords: Spare Parts Management, Real Option Analysis, Spare Part Classification

\section{INTRODUCTION}

We address the problem of spare parts management of capital intensive equipment like aircraft, engine, power plant etc. It has complex structures and the operating time of the equipment should be maximized so as to maximize the return on investments. One way to achieve high operational readiness (or availability) is to acquire enough spare parts. However, the spares are costly and it is seen that the investment in spare parts over the life of the equipment exceeds the investment made for the procurement of the capital goods many folds. Hence, the problem of spare inventory is critical and not a trivial issue.

Although after-sales service support and spare parts management is providing competitive advantage to firms but mostly firms are managing them by adopting standard inventory control methods without addressing the typical characteristics of spare parts. Syntetos and Boylan (2008) has described the differences between the production environment and spares environment and Syntetos et al. (2009) mentions spares classification is an ignored area of research. Kampen et al. (2010) provides a comprehensive review of the criteria for SKU Classification in the production and operations environment with specific references to the classification of spare parts. Few studies which throw challenging perspectives for spare part classification study include: Talluri et al.(2004) work on the basis of variability, Cavalieri et al.(2008) focus on the impact of shortage of spare parts, Porras and Decker (2008) inclusion of demand criticality in an oil refinery, Teunter et al.(2010) argument of utilization of holding cost. The impact of shortages and breakdown patterns which are unique characteristics of spare part, makes it difficult to assess good strategies for the management of spare parts. In this study, we have changed the vantage point from which we look at spares management system. We have proposed the concept of 'Spare Life Time Value' (SLTV) and recommended allocation of resource based on SLTV. This idea has been mooted, by drawing an analogy to the customer life time value. Instead of looking from the vantage point of the equipment where the spare is used, the spare in our study is being looked as a cost and investment in this resource has to be justified. In a study by Cohen et al. (2006a), the concept of 'Service Asset Management' and 'Dynamic Asset Deployment' has been introduced. It proposes flexibility and responsiveness in delivering cost effective service. This seminal paper throws the idea of maximum service from their investment in service resources by redeploying the assets with strategic risk-based forecasts and decisions. In our work we are trying to consider spares as 'Service Assets' and evaluate the value of this asset which can be used as the basis of deployment.

From the academic perspective this work contributes to the research in the area of Spare parts management. This work provides a new vantage point by considering investment in spare based on its contribution to profitability. This is the first research which gives the concept of value of a spare and based on this concept the allocation of spares can be done in a scarce resource scenario and ascertaining the value of the contract. In the industrial scenario, we propose to utilize this as a classification tool to enable managers to make strategic discretionary decisions based on the investment and the uncertainty involved. It is not possible to stock all items and so there should be a basis of ranking these spares which is based on the value contributed by the spare. Value of a spare is based on the core benefits or the payoff and the likelihood of demand. This model could also be applied to other similar equipment intensive industries and the robustness of the model can be tested. 
The paper is organized as follows: The next section deals with relevant literature review. Then, the new approach has been explained, and a model has been proposed. Subsequently, an industrial case study is presented to illustrate the problem of spare resource allocation in an Indian railway engine maintenance shed. In the final section, we draw conclusions and discuss the academic and industrial contribution with the scope for future research.

\section{LITERATURE REVIEW}

The literature review provided by Kennedy et al. (2002) gives a comprehensive overview of the studies available in the area of spare parts management. The seminal work in this area is the METRIC model (Multi-Echelon Technique for Recoverable Item Control) proposed by Sherbrooke (1968). Most mathematical models are derivatives of the above model and are largely optimization models which are either too complex, or oversimplified and abstract, thus reducing their usefulness for managers. Lackes (2009) mentions the gozintograph which considers parts as quasihierarchical and having its own existence which have to be recognized in enterprise planning. The other approach to addressing this problem is by adopting the classification schemes as a tool. These are very popular approaches with industry (Braglia et al., 2004). The ABC-classification based on the Pareto's principle is the classification scheme mostly used to manage spare parts inventory. The VED (Vital, Essential, and Desirable) classification based on the criticality of the item is also quite popular. Based on demand classification spares can be classified as: fast moving, slow moving and non-moving items. Studies in Multi- Criteria Inventory Classification (MCIC) of spares have included various factors such as: stock-out penalty cost, demand distribution, stock ability, substitutability, scarcity etc. AHP (Analytical Hierarchical Process) has been used in many studies where a scalar measure of importance has bleen determined by subjective rating of the criteria (Ramanathan, 2006). Flores and Whybark $(1986,1988)$ and Flores et al. (1992) have also applied AHP to the multi-criteria inventory classification and have devised a criterion based on the usage value, criticality and the $A B C$ classification. Molenaers et al. (2012) adopted a classification based on criticality wherein the proposed model converts the different variables affecting criticality into a single variable which has been shown through a case study. Baccheti and Saccani (2012) explore the classification for stock control for durable goods. Heinecke et al. (2013) has presented classification based on the underlying demand pattern and appropriate forecasting adopted for the same. Roda et al. (2014) has provided an extensive review of multi criterion classification for spare parts based on their peculiarity. It also explores the barriers between theory and practice. In the present study, the multi criterion has been reduced to a univariate and consistent measure and the determined scalar value becomes the denomination on which we can rate the different spares and have a control. De Almeida (2001) has applied AHP to formulate integrated criteria which includes factors like cost of lost production, inventory constraints, safety and environmental issues etc. Gajpal et al. (1994) illustrate the use of Saaty's AHP to evaluate the criticality of spares. Syntetos et al. (2005) has tried to understand the demand pattern of the spares and used it as the basis of classification. Ernst and Cohen (1990) proposed a general grouping method that can be used to define group based operational control policies. Huiskonen (2001) classified spares into criticality, specificity, demand pattern and usage and then in the next study introduced process criticality and control criticality (Huiskonen et al., 2003). It can be concluded from the literature review that the studies on the METRIC method focused on the objective of either maximization of availability of the equipment or minimization of cost. The classification schemes though popular address some characteristics of spare and are not holistic.

\section{SPARE LIFE TIME VALUE - THE NEW APPROACH}

What is the need of a spare part? What is the worth of a spare part? What considerations should guide the spares provisioning decision or rather investment in spare parts? These questions need intense deliberations, if we are working in a resource crunch environment.

In this study we have drawn an analogy to the marketing concept of "Customer Life Time Value" which is the optimal allocation of resources and efforts across various profitable customers to ensure cost effectiveness. Customer lifetime value of a customer for a firm is the net profit or loss to the firm, considering the transactions made throughout its entire life of that customer with that firm. Hence, the lifetime value of a customer for a firm is the net of the revenues obtained from that customer over the lifetime of transactions with that customer minus the costs, taking into account the time value of money (Berger and Nasr, 1998). This Customer Life Time Value framework has been utilized as the basis for customer selection and resource allocation (Jain and Siddhartha, 2002). It is also used to generate customer level strategies and optimize firm's performance especially for customer selection, customer segmentation, optimal resource allocation, purchase sequence analysis and targeting profitable prospects (Venkatesan and Kumar, 2004).

Here, in this paradigm, the spare part has been considered as an entity that provides the firm with a stream of revenue (or cost savings) and based on this characterization we have said that spare can be considered as an asset. Although the revenue generated cannot be directly calculated but it can be estimated and predicted based on the expected value. We propose 'Spare Life Time Value' (SLTV) as the objective measure of the worth of the spare. It shall reflect the contribution of the spare towards profitability. It can be used to rank the spares on the basis of their contribution and thus guide the organization in strategic allocation of the resources because we are not working in an unlimited resource environment and segmentation strategy is the key to manage provisioning profitably.

To operationalize this construct of 'Spare Life Time Value' we shall use Real Option analysis (ROA). It considers all future investment opportunities along the value chain, allowing a dynamic assessment of investments. Option Analysis has been utilized for determining the 'Customer Life Time Value' (CLV) by Levett et al. (1999) and Haenlein et al. (2006). Drawing an analogy to this 
Option value, our construct the 'Spare Life Time Value' can be interpreted as a product of the Contribution and Likelihood of Exercise. Therefore, for a spare part, it is a function of the payout expected if the option is exercised and the likelihood of exercise as given by Levett et al. (1999).

\section{REAL OPTION FORMULATION FOR SPARE PARTS}

Spare parts are conventionally considered a liability for the organization and a dead inventory. It becomes valuable abruptly, in the event of a breakdown which is uncertain. We can think of a stepney tyre, which is a dead weight which is carried by the driver and suddenly becomes valuable when there is a puncture. Functionally, the value of this spare lies in the loss it avoids by its presence at that time. Thus, on analyzing the attributes of spare parts, there are two striking characteristics, which sum up the essence of a spare part: huge impact of shortages and the stochastic and uncertain demand pattern (unpredictability). These characteristics can be classified as shown in Figure 1 as:

1. Consequentiality referring to the consequence of the stock-out which can be severe.

2. Volatility referring to the unpredictability of the demand for spares.

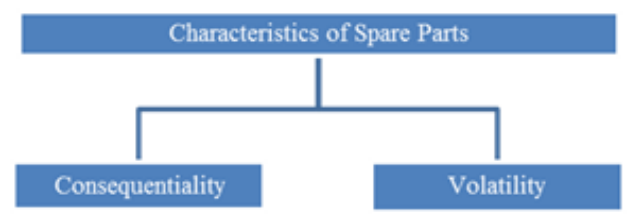

Figure 1. Classification of Characteristics of Spares

\section{UNDERSTANDING SPARE BREAKDOWN IN A DYNAMIC ENVIRONMENT}

The management of spare parts is rather difficult because the demands can be very low (as small as once in a year or even lower), while the consequences of a stock-out can be severe. If we consider the spare part as an asset, there are only two scenarios - Breakdown and No Breakdown.

Let Probability of scenario breakdown $=\mathrm{p}$;

Probability of scenario of no breakdown $=(1-p)$;

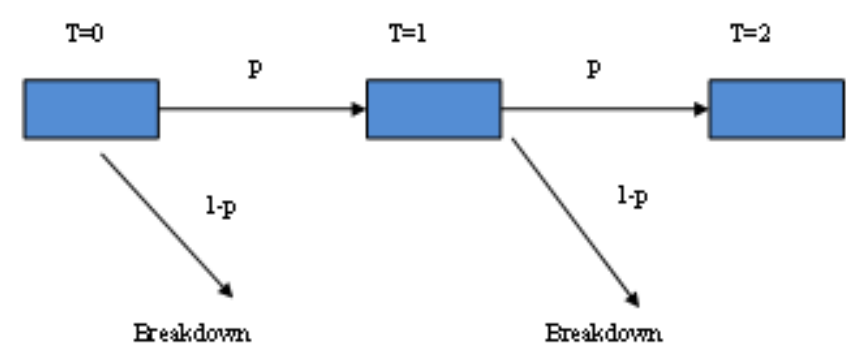

Figure 2. Multi period Breakdown Phenomenon of Spares

When a breakdown will occur is uncertain and exogenous which is a basic condition for application of option theory. When a breakdown will occur is uncertain and exogenous which is a basic condition for application of option theory. In option theory, an option gives the holder the right to buy an underlying asset at a predetermined price, at a later date. The pay-off depends on the underlying asset price at the time of exercise of option (Copeland and Antikarov, 2001). Drawing an analogy, we consider a similar phenomenon for spares breakdown. It is found that the spare part is required in the event of breakdown, but the event of a breakdown is uncertain and exogenous and hence 'unpredictable'. The function of a spare is to minimize the downtime which averts a huge cost of stopped operations, goodwill etc. which is a measure of 'consequentiality'. Therefore, the major contribution for a spare part in business is not from the price but the value it provides, which increases drastically as a breakdown occurs. Here, the value of the spare is considered as the volatile variable which rises sharply as the breakdown takes place. Accordingly, we can infer that the spare parts can be modeled as 'call option to invest'. Further, this would be an American Call option because breakdown can occur anytime during the life of the option period. If we consider this model of an option, the moment a breakdown occurs the spare falls in the money and has to be exercised.

Hence, the spare has value only in an event of a breakdown otherwise it is worthless. This implies that the usefulness of spare, is the volatile element in our study, and this is governed by breakdown which is uncertain. We can assume that as soon as the breakdown occurs, the value of the option increases to a large value $\mathrm{P}$. We shall consider the value of the spare as the volatile variable and not its price. We can consider the variation of the value of the spare which remains negligible till the breakdown takes place and rises sharply as is depicted in the Figure 3.

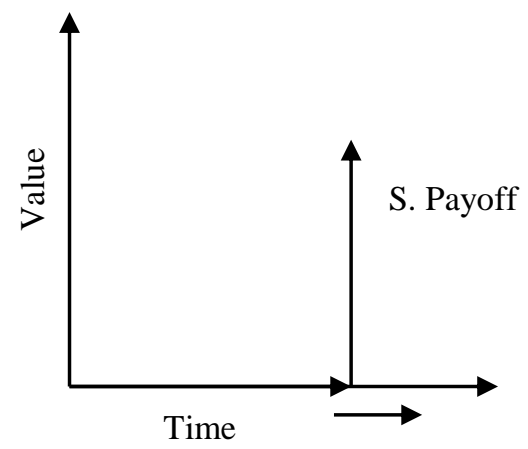

Figure 3. Spare part-real option formulation

The next exercise undertaken is to determine the intrinsic value of the spare part in the event of breakdown i.e. the value to which the spare part rises in the event of a breakdown. We refer to the concept of Consequentiality mentioned above and devise the term of Spare asset value that gives the value ' $S$ ' (payoff in the option parlance) to which the item shall rise in the event of a breakdown. In this model the payoff that we receive is in terms of the cost averted in the prevention of a stock-out situation which could have had severe consequences and hence represents the intrinsic value of the spare part. In this study, as we are considering a basic skeletal model for determining the value 
of the spare.

The asset value of the spare is considered as the volatile variable which rises sharply as the breakdown takes place. There are only two states - either there is a breakdown or else there is no breakdown. First the option value is determined for one time period and then it has been extended to cover multiple time periods. Using options, the value can be viewed as a derivative of input cost, output yield, time and uncertainty. The uncertainty component has been addressed by using probability and time variables. The significance of this modeling exercise and our intent in this work is to provide the foundation for determining the value created in this real option formulation. In option parlance, the underlying asset price $\mathrm{S}$ of the call option can be viewed as the aggregate of the monetary and the nonmonetary value provided by the spare. The exercise price $\mathrm{K}$ is the purchase price of the spare which is required to be paid. A call options pays off at expiration when the stock price, $S$, exceeds the exercise price $X$, otherwise it is worthless and is represented as: MAX [S-X, 0].

The option value created can be interpreted as a product of the contribution and likelihood of exercise. Therefore, for a spare part, it is a function of the payout expected if the option is exercised and the likelihood of exercise as given by Levett et al. (1999). Intuitively option value gives the expected contribution from a spare part. These two components Payout and likelihood of exercise have been mapped to the concept of Consequentiality and Volatility as proposed by Sharma and Singh (2010). Considering a skeletal model, the basic payoff or yield for a spare part comes from the Consequentiality head and is the penalty cost and the implementation cost be the cost of the spare. The Criticality of a spare part is a measure of the stock-out cost or the damage suffered due to the absence of the part and let us consider a factor $M$ such that the product of Criticality and Constant gives the per period stock out cost .

\section{Critical factor $*$ Lead Time $*$ Constant $M$}

$$
=\text { Total Stock }- \text { out Cost }=\text { Pay off }
$$

Volatility as defined in this work is a measure of the uncertainty in spares breakdown. It is operationalized through the variance and mean of the breakdown pattern. Rate of interest and time period to be considered is same across all parts and is exogenous and form part of the operational environment. The Representative examples of use of Black-Scholes Model in Real Options include Amram and Kulatilaka (1999). Basil et al. (2003) and Harmantzis (2007) have applied this model to telecom field. The underlying assumption for the Black-Scholes Closed form Model is that the asset follows a random walk and is in a risk-neutral world. Copeland and Antikarov (2001) have proposed the Market Asset Disclaimer which assumes that the asset value is the underlying security and it should be treated as it were traded in the market by considering the risk free rate for discounting. The formula is easy to use and available even on some calculators. The Black and Scholes Model for valuation of options is one limiting case of the Binomial Model. The underlying stock price is assumed to follow a Geometric Brownian Motion. The value of a call option in the Black-Scholes model (Hull, 2002) can be expressed as follows.

Given, $\mathrm{S}=$ current value of the underlying asset,

$\mathrm{K}=$ strike price of the option,

$\mathrm{T}=$ time to expiration of the option (in years), $\mathrm{rf}=$ risk free interest rate corresponding to the life of the option,

$\mathrm{r}=$ discount rate,

$\sigma^{2}=$ volatility of the underlying asset,

The Black-Scholes model can be written as

Value of the call $=\mathrm{SN}\left(\mathrm{d}_{1}\right)-\mathrm{Ke}^{-\mathrm{rf*}(\mathrm{t})} \mathrm{N}\left(\mathrm{d}_{2}\right) \ldots(1.1)$

$$
\text { Where, } \begin{aligned}
\mathrm{d}_{1}=\left[\ln \left(\frac{\mathrm{s}}{\mathrm{K}}\right)+\left(\mathrm{r}+0.5 * \sigma^{2}\right) * \mathrm{t} / \sigma \sqrt{\mathrm{t}}\right. \\
\mathrm{d}_{2}=\mathrm{d}_{1}-\sigma \sqrt{\mathrm{t}}
\end{aligned}
$$

Where, $\mathrm{N}(\mathrm{x})$ is the cumulative distribution function for a standardized normal distribution. It can be interpreted as the probability that a variable with a standard normal distribution, $\Phi(0,1)$, will be less than $x$. The probabilities, $\mathrm{N}\left(\mathrm{d}_{1}\right)$ and $\mathrm{N}\left(\mathrm{d}_{2}\right)$ that feature in the Black -Scholes model represent in approximate terms, the range of probability that the option will be in the money at expiration i.e., the probability that $S>K$. The variable 'volatility' sigma ' $\sigma$ ' which is computed from the natural $\log$ of the relative returns and is a measure of relative risk (Mun, 1997) addresses the uncertainty issue and accounts for risk in the Black-Scholes. The Black-Scholes model evaluates the European option. In our case there is no dividend payment and hence there is no incentive to exercise early. In zero dividend cases it is found that the American Option is equivalent to European option as early exercise is never

\begin{tabular}{|c|c|c|}
\hline Item & Shaft & \\
\hline \multicolumn{3}{|c|}{ Breakdown pattern given in Table } \\
\hline Time $(\mathrm{t})$ & 2 & \\
\hline $\begin{array}{l}\text { Risk } \\
\text { Free (rf) }\end{array}$ & $5 \%$ & \\
\hline $\begin{array}{l}\text { Discount } \\
\text { Rate }(r)\end{array}$ & $15 \%$ & \\
\hline $\mathrm{S} / \mathrm{K}$ & 3.5 & \\
\hline Asset $S_{t}$ & 2.593 & EXP $\left(-r^{*} t\right)^{*} s$ \\
\hline $\begin{array}{l}\text { Exercise } \\
\mathrm{K}_{\mathrm{t}}\end{array}$ & 0.905 & $\operatorname{EXP}\left(- \text {-rft}^{\star}\right)^{\star} \mathrm{K}$ \\
\hline Sigma & 0.741 & SQRT(LN(1+POWER(s.d./Mean),2))/sqrt(t) \\
\hline $\begin{array}{l}\text { Option } \\
\text { Value }\end{array}$ & 1.798 & $\mathrm{~N}\left(\mathrm{~d}_{1}\right)^{*} \mathrm{St}-\mathrm{N}\left(\mathrm{d}_{2}\right)^{*} \mathrm{Xt}$ \\
\hline$d_{1}$ & 1.815 & $\begin{array}{l}\left(\mathrm{LN}(\mathrm{S} / \mathrm{K})+\left(\mathrm{rf}+\mathrm{POWER}(\text { Sigma }, 2)^{*} 0.5\right)^{*} \mathrm{t}\right) /\left(\mathrm{Sigma}^{*} \mathrm{SQ}\right. \\
\mathrm{RT}(\mathrm{t}))\end{array}$ \\
\hline$d_{2}$ & 0.767 & $\mathrm{~d}_{1-}\left(\mathrm{SQRT}(\mathrm{t})^{*}\right.$ Sigma $)$ \\
\hline $\mathrm{N}\left(\mathrm{d}_{1}\right)$ & 0.965 & $\operatorname{NRMDIST}\left(\mathrm{d}_{1}\right)$ \\
\hline $\mathrm{N}\left(\mathrm{d}_{2}\right)$ & 0.778 & $\operatorname{NRMDIST}\left(d_{2}\right)$ \\
\hline
\end{tabular}
optimal (Black and Scholes, 1973).

Table 1. Calculation as per Mathew et al. (2007)

\section{PROPOSED OPTION VALUATION MODEL}

The proposed model can be mapped to the study by Huiskonen (2001), who categorizes the spares based on its characteristics viz. value and criticality into different control situations and specifies for each of these control situation different strategies and policies. Further analyzing this study in the light of Huiskonen's work, these observations emerge:

i) 'Criticality' as mentioned by Huiskonen is a 
variable of 'Consequentiality' proposed in our work.

ii) 'Value' as envisaged by Huiskonen is a product of 'Cost' and 'Usage'. Cost contributes to 'Consequentiality' and Usage contributes to 'Volatility' in this study.

iii) Consequentiality considers criticality vis-à-vis cost while Volatility considers demand variability vis-àvis total demand in the demand pattern.

This analysis is in sync with Huiskonen's model and appends it further by considering more attributes and also thus provide a quantitative framework to enable managers to appreciate and utilize the classification. These interpretations lead us to devise an option valuation model for the decision makers, which are given in Fig.4. The critical input variables for this model are: Consequentiality and Volatility. Based on this, the decision maker can choose: to stock, not to stock, option model or regular supplies from vendor. The two variables can take either a high value or a low value. Depending on these values the option value created is evaluated. Based on the matrix class in which the particular spare falls which depends on the cost, breakdown pattern and the consequential loss that occur, the spares can be allotted different treatment. Correlating with the Huiskonen's strategy for spares management the decision model has been suggested.

1. $\mathrm{H}_{\mathrm{C}} \mathrm{H}_{\mathrm{V}}$ : This indicates High consequentiality and High volatility.

For these items the $\mathrm{S} / \mathrm{K}$ value is high i.e. the spare asset value which the spare attains is high in the event of a breakdown. Also, the uncertainty is high and so the option value will be high. Huiskonen has suggested several users' cooperative stock pools (for very low demand). A cooperative stock pool is also like an option model wherein spare is issued on demand. A similar arrangement can be operationalized with spare service providers based on option model. Option Model is the best Spares management strategy in this case where pricing is based on usage.

2. $\mathrm{H}_{\mathrm{C}} \mathrm{L}_{\mathrm{V}}$ : This indicates High consequentiality and Low volatility.

For these items the $\mathrm{S} / \mathrm{K}$ value is high but uncertainty is low which means certainty is high. Huiskonen has suggested User's decentralized safety stocks and generous replenishment lot sizes. The choice is the stocking model as there is fairly regular consumption and less of downward risk of spare sitting idle and becoming obsolete. We propose that for high cost and low demand items stocking is more suitable. The option value is high because of the high payoff involved.

3. $\mathrm{L}_{\mathrm{C}} \mathrm{H}_{\mathrm{V}}$ : This indicates Low Consequentiality and high volatility.

These items have low $\mathrm{S} / \mathrm{K}$ value but high uncertainty. The absence of the spare has not much consequence and the demand pattern is erratic, not stocking is the proposed strategy.

4. $\mathrm{L}_{\mathrm{C}} \mathrm{L}_{\mathrm{V}}$ : This indicates Low Consequentiality and Low Volatility. As the Consequentiality is not high and there is certainty the choice is between 'may not stock' or 'stock' but option model is not suitable for such items. The demand being fairly regular and stocking with normal ordering policy based on EOQ or Vendor Managed Inventory can be the ideal strategy.
The Proposed Option valuation model can be used by the decision makers wherein the critical input variables are: Consequentiality and Volatility. Based on this, the decision maker can choose: to stock, not to stock or adopt an option model approach (This means that only when there is a breakdown a spare is issued. For a practitioner a cooperative stock pool is also like an option model wherein spare is issued on demand operationalized with spare service providers).

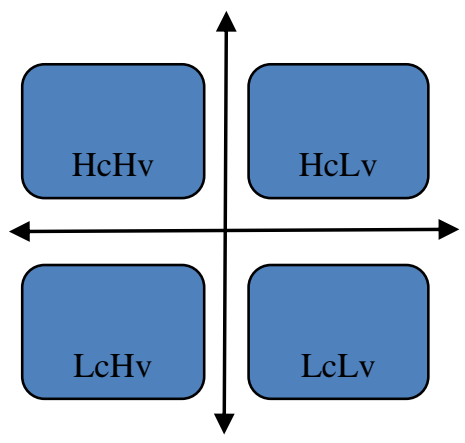

Fig. 4. Inventory Classification

The proposed course of action for the various classes is as follows:

1. High Consequentiality High Volatility $(\mathrm{HcHv})$ : Option Model is the best provisioning strategy

2. High Consequentiality Low Volatility HcLv: Stocking is the best provisioning strategy.

3. Low Consequentiality Low Volatility LcLv: No stock- VMI is the best provisioning strategy.

4. Low Consequentiality High Volatility LcHv: No stock is the best strategy.

\section{AN INDUSTRIAL CASE STUDY}

The previous section gives the theoretical framework for determining this Option Value. In this section an industrial case study has been included to illustrate its use in practical settings. The case study considers "ABC (a fictitious company) an Airline Industry.

The airline industry is highly regulated and the existing system is based on the established provisioning guidelines. Traditionally, the Airlines have been conservative and overstocked in order to provide adequate and uninterrupted service. All airlines are facing a severe crisis and are bleeding in the present scenario. The bottom line of the Airline is under pressure and all cost has to be scrutinized and minimized. The guiding objective of the airline can be prioritized as Maximize Flight Safety, Maximize Revenue, Minimize Cost, on time Performance.

Objective of the Materials Manager is Proper Control of Procurement and Provisioning of spares. They define the procurement policies, procedures, standards and guidelines. Traditionally, the Airlines have been conservative and overstocked in order to provide adequate and uninterrupted service.

The Steps in the Present practice is to foremost classify Spares in the Minimum Equipment List (MEL) which considers whether the spare is an Aircraft on Ground (AOG) item. The Aircraft Spares are broadly categorization into: Rotables and Non-Rotables. Rotables are Components 
having a known overhaul life in terms of hours between overhauls and capable of undergoing infinite number of overhauls. Non-Rotables or expendables are those items which are subject to one time use. Some items have been classified as 'Insurance items' which are held as a precaution against serious delay should an accident or other contingency arise. These items include Flaps, Wing Tips etc.

Provisioning of Non-Rotables and Inventory Control is done by resorting to A-B-C Analysis on the basis of Annual Consumption Value. A-B-C Analysis as an Inventory control Technique is used for effective inventory control .AB-C classes are determined on the basis of past annual consumption value. The cost of each item is multiplied by consumption (quantity consumed) in a given period of time (year) and items are then listed in the descending numerical order of consumption value and segregated into A-B-C classes. In this process, ' $A$ ' class represents relatively a small number of items $(15 \%)$ and accounts for sizeable percentage $(60 \%)$ of total annual consumption. 'B' Class will account for more number of items $(30 \%)$ and about $35 \%$ of consumption value. ' $\mathrm{C}$ ' Class will include a large number of items (55\%) whose annual consumption value is comparatively small (approximately $5 \%$ ).

The A-B-C classification limits for the Aircraft and the suggested stock levels are as follows:

A Class Items: Unit value more than INR 1 lakh and stock level proposed is six months

B Class Items: Unit value INR 15,000.00-1 lakh and stock level proposed is nine months

C Class Items: Unit value below INR 15,000.00- and stock level proposed is 15 months

To address the utilization aspect of spare items, the airline classifies the items into moving (which have moved in the last two years), non-moving (which has moved between 2-5 yrs) and surplus (beyond $5 \mathrm{yrs}$ ). The reclassification is done once a year at the end of a year. Thus, items have been ranked on the basis of annual usage for ABC Classification, Criticality for VED classification and then FSN classification.

Altered process: It is observed that the above practice has separate single criteria classification and do not individually capture the essence of the spare part entirely, especially for non-rotables. On analyzing the spares behavior functionally, it is observed that it does not generate any cash flows but prevents penalty cost. As mentioned earlier, the payoff for a spare part is the Spare asset value which is the stock out cost of the spare The Criticality of a spare part is a measure of the stock-out cost or the damage suffered due to the absence of the part period stock out cost for a spare. The implementation cost or the expenditure required to acquire the asset for the spare is the cost of the spare. Assuming that the net revenue per passenger is INR 5000.00.There are 150 seats offered and the net occupancy is $66.67 \%$. The aircraft operates $10 \mathrm{legs}$ in a day. Hence revenue per day per aircraft is INR 50,00,000.00. The exogenous data has been considered similar to the previous exercise i.e. the time period for the study is 2 years. The value for time and discount rates shall remain constant across all data and do not affect the ranking. Two discount rates; one, the market rate for the asset, $r$, and the other, risk free interest rate, $\mathrm{rf}$, for investment have been considered.

The data has been collected for spare parts which are given in Annexure C. On observing the data, it is found that most of the data falls under A-Class items by the present system. Items in Class $\mathrm{B}$ and Class $\mathrm{C}$ have been shown separately. If too many items are classified as A (which demands more attention), the purpose of classification itself is defeated and so the classification limits should be constantly reviewed.

The first step is to determine the value of $\mathrm{S} / \mathrm{K}$ which gives the consequentiality of the spare part. $\mathrm{S}$ is the spare asset value or the stock out cost. The next step is to determine the value of sigma which addresses volatility of the spare part. After determining the volatility and the S/K value for each spare, the Black and Scholes formula has been used to find the option value of the spare.

We propose to develop a matrix which addresses multi criterion and provides the strategy for each spare. Based on the above process the spares have been classified in the Table. Spares which directly affect the flight safety have high consequentiality while passenger amenities fall lower on consequentiality level. Air Frame Spares mostly fall in the $\mathrm{HcHv}$ category. Avionics Spares fall in HcLv category as the breakdown is frequent. Galley equipments fall in $\mathrm{LcHv}$ category while Passenger Amenities can be considered as LcLv. Items like Cabin pressure amplifier, which would have been class $\mathrm{B}$ items in the traditional system is $\mathrm{H}_{\mathrm{c}} \mathrm{H}_{\mathrm{v}}$ in the proposed classification. In this case Windshield which is an A class item falls in LcHv item in our case because it is the ratio of consequentiality to the cost which is considered and the volatility is high. Similarly there are different lights but they offer a different treatment. These are C-class items. Based on the functionality, the items have different consequentiality. Cockpit Lights and Landing and Taxing lights have very high consequentiality as compared to the cabin reading light which affects the single passenger only and hence has low consequentiality. The demand pattern also decides the strategy for the spare. As is the case in the $\mathrm{ABC}$ analysis after ranking, the cut off rank for $\mathrm{A}, \mathrm{B}$ and $\mathrm{C}$ classes are determined based on the management judiciousness. If too many items are classified as A (which demands more attention), the purpose of classification itself is defeated. Similarly, the option classification also will depend on the risk taking ability of an organization. Items with high option values are to be stocked. Items with option value around 1 are apt for option arrangement and below that are best handled by no stocking arrangement.

\section{RESULTS AND DISCUSSION}

The results of the model i.e. the ranking based on option value, are able to capture the essence of spare parts i.e. 'uncertainty of breakdown' and the implicit payoff 'reduction of operational losses' by the presence of the part. As we are working in a resource crunch environment, provisioning spares on the basis of the value that can be derived from these spare parts thus capturing the essence of spares, forms the basis of this classification. As the option value gives information of the worth of the spare, which the spare is expected of delivering, this seems an appropriate basic of resource allocation. The ingenuity lies in the appropriate determination of the penalty loss, which is critical in determining the option value. Managerial judiciousness is required in estimating the same and so the results will be as robust as the value of these losses. 


\section{CONTRIBUTION}

From the academic perspective this work broadly contributes to the research in the area of Spare Parts Management by proposing a methodology to determine the valuation of spare. It addresses two research directions: The first research area that has been opened by this work relates to determining the value of a spare. This paper provides a new vantage point by considering spare as an investment. The second one is as proposed by Cohen et al. (2006a) the concept of 'Service Asset Management' and 'Dynamic Asset Deployment' which considers flexibility and responsiveness in delivering cost effective service. Therefore, we can also look at option contracts and use this value for considering the viability. Thus, the operational strategic angle has been provided in deployment of spares. Further, it supplements the literature in Multi attribute decision making (MADM) specifically for Spare Parts Management.

From the practitioners perspective the 'Spare Life Time Value' can become a metric to ascertain its Spare Life Time Value. Real Option analysis is a means to quantify risk and uncertainty of individual cases on a risk-return framework and is a promising valuation tool for strategic corporate investment decision.

\section{CONCLUSION AND FUTURE RESEARCH}

We propose to utilize this as a classification tool to enable managers to make strategic discretionary decisions based on the consequentiality and the uncertainty involved. It is not possible to stock all items and so there should be a basis of ranking these spares which is based on the value contributed by the spare as $100 \%$ spares cannot be stocked. Value of a spare is based on the core benefits or the payoff and the likelihood of demand. We have tried to capture both these characteristics in our model. Real Option Analysis has been identified in the literature as a quantitative means to evaluate the flexibility inherent in the decision making process. By adopting a real options framework we develop a model that incorporates the demand and the financial uncertainties involved. The value derived from this asset in terms of asset utilization determines the viability of this investment. Although valuing options embedded in real life cases with the help of Black-Scholes Model is a systematic way of determining the value of an option but often it requires some assumptions. Our approach focuses on demand because the primary uncertainty lies with demand. In case the failure distribution happens to be different from the normal distribution, the likelihood of exercise can be determined for the given distribution and the value created can be determined. The base model can further be modified to address other aspects of spares management. As the B-S model is widely available even on calculators, widespread acceptability should not be an issue. This model could also be applied to other similar equipment intensive industries and the robustness of the model can be tested. The future research in this area would include adding complexity to this model by incorporating complex behavior of spare and environment influences. This model can also be used in determining the value of spare contracts and can contribute to assessing the material cost of performance based contracts.

\section{REFERENCES}

Amram, M., and Kulatilaka, N. (1999), Real Options: Managing strategic investment in an uncertain world, Harvard Business School Press.

Bacchetti, A., and Saccani, N. (2012), Spare parts classification for stock control: Investigating the gap between research and practice. Omega, 40(6), pp. 722-737.

Berger, P.D., and Nasr, N.I. (1998), Customer Lifetime Value: Marketing Models and Applications. Journal of Interactive Marketing, 12, pp. 17-30.

Black, F., and Scholes, M. (1973), The pricing of options and corporate liabilities. Journal of Political Economy, 81, pp. 637-659.

Boylan, J.E., Syntetos, A.A. and Karakostas, G.C. (2006), Classification for forecasting and stock control: a case study. Journal of the Operational Research Society 59, pp. 473-481.

Baraglia, M., Grassi, A., and Montanari, R. (2004), Multi-attribute classification method for spare- parts inventory management. Journal of Quality in Maintenance Engineering, 10(1), pp. 55-65.

Cavalieri, S., Garetti, M., Macchi, M. and Pinto, R. (2008), A decision- making framework for managing maintenance spare parts. Production Planning and Control, 16(8), pp. 774-84.

Cohen, M.A., Agrawal, N., and Agrawal, V. (2006a), Achieving Breakthrough Service Delivery Through Dynamic Asset Deployment Strategies. Interfaces, 36 (3), pp. 259-271.

Copeland, T., and Antikarov, V. (2001), Real Options: A Practitioner's Guide, McGraw Hill, New York.

De Almeida, A.T., (2001), Multi criteria decision making on maintenance spares and contracts planning, European Journal of Operational Research, 129, pp. 235-241.

Ernst, R., and Cohen, M.A. (1990), Operations related groups (ORG): a clustering procedure for production/inventory systems. Journal of Operations Management, 9(4), pp. 574598.

Flores, B.E., and Whybark, D.C. (1986), Multi criteria ABC analysis. International Journal of Operations and Production Management, 6(3), pp. 38-46.

Flores, B.E., and Whybark, D.C. (1988), Implementing multicriteria $\mathrm{ABC}$ analysis. Engineering Costs and Production Economics, 15, pp. 191-195.

Flores, B.E., Olson, D.E., and Dora, V.K. (1992), Management of multicriteria inventory classification. Mathematical and Computer Modelling, 16(12), pp. 71-82.

Gajpal, P., Ganesh, L., and Rajendran, C. (1994), Criticality analysis of spare parts using the analytic hierarchy process. International Journal of Production Economics, 35, pp. $293-$ 298.

Haenlein, M., Kaplan, A.M., and Schoder, D. (2006), Valuing the Real Option of Abandoning Unprofitable Customers when calculating Customer Life time value. Journal of Marketing, 70, pp. 5-20.

Harmantzis, F.C., and Tangutin, V.P. (2007), Investment decisions in the wireless industry applying real options. Telecommunications policy, 31, pp. 107-123.

Heinecke, G., Syntetos, A.A., and Wang, W. (2013), Forecasting based SKU classification. International Journal of Production Economics, 143(2), pp. 455-462.

Huiskonen, J. (2001), Maintenance spare parts logistics: Special characteristics and strategic choices. International Journal of Production Economics, 71, pp. 25-133.

Huiskonen, J., Niemi, P., and Pirttillä T. (2003), An approach to link customer characteristics to inventory decision making. International Journal of Production Economics, 81-82, pp. 255-264.

Hull, J.C. (2002), Options, Futures and Other Derivatives, Prentice Hall of India Pvt. Ltd.

Jain, D., and Siddhartha, S. (2002), Customer lifetime value 
research in marketing: A review and future directions. Journal of Interactive Marketing, 16(2), pp. 34-45.

Kampen, T.J., Akkerman, R., and Donk, D.P. (2012), SKU classification: a literature review and conceptual framework. International Journal of Operations and Production Management, 32(7), pp. 850-876.

Kennedy, W.J., Patterson, J.W., and Frendendell, L.D. (2002), An overview of recent literature on spare part inventories. International Journal of Production Economies, 76(2), pp. 201-215.

Lackes R. (2009), Architecture and Functioning of a Supply Chain Enterprise Resource Planning System. Operations and Supply Chain Management, 2(3), pp125-135.

Levett, P., Michael, P., Nel D., Leyland P., Berthon P., and Money, A. (1999), Towards an application of option pricing theory in the valuation of Customer relationship. Journal of Strategic Marketing, 7(4), pp. 275-284.

Martin, H., Syntetos, A.A., Parodi, A., Polychronakis, Y.E., and Pintelon, L. (2010), Integrating the spare parts supply chain: an inter-disciplinary account. Journal of Manufacturing Technology Management, 21 (2), pp. 226-245.

Molenaers, A., Baets, H., Pintelon, L., and Waeyenbergh, G. (2012), Criticality classification of spare parts: A case study. International Journal of Production Economics, 140(2), pp. 570-578

Mun, J. (2002), Real options Analysis Tools and Techniques for valuing Strategic Investments and Decisions, Wiley Finance Series, 2002.

Porras, E., and Dekker, R. (2008), An inventory control system for spare parts at a refinery: an empirical comparison of different reorder point methods. European Journal of Operations
Research, 184(1), pp. 101-32.

Ramanathan, R. (2006), ABC inventory classification with multiple-criteria using weighted linear optimization. Computers \& Operations Research, 33, pp. 695-700.

Roda, I., Macchi, M., Fumagalli, L., and Viveros, P. (2014), A review of multi-criteria classification of spare parts : From literature analysis to industrial evidences. Journal of Manufacturing Technology Management, 25(4), pp. 528 549.

Sharma, M.G., and Singh, K.N. (2010), A real options approach to Spares Management. Udyog Pragati, 34(4), pp. 1-9.

Sherbrooke, C.C. (1968) METRIC: A multi-echelon technique for recoverable item control. Operations Research, 16, pp. 122141.

Stores Manual, Indian Railways;

Syntetos, A.A., Boylan, J.E. and Croston, J.D. (2005), On the categorization of demand patterns. Journal of Operations Research Society, 56, pp. 495-503.

Syntetos, A.A., Keyes, M. and Babai, M.J. (2009), Demand categorization in a European spare part logistics network. International Journal of Operations and Production Management, 29(3/4), pp. 292-316.

Teunter, R.H., Babai, M.Z. and Syntetos A.A. (2010), ABC Classification: service levels and inventory costs. Production and Operations Management, 19(3), pp. 343-52.

Venkatesan, R., and Kumar, V. (2004), A Customer Life Time Value Framework for Customer Selection and Resource Allocation Strategy. Journal of Marketing, 68, pp. 106-125.

Williams, T.M. (1984), Stock Control with Sporadic and SlowMoving Demand. Journal of Operational Research Society, 35(10), pp. 939-948.

Mohita Gangwar Sharma is Associate Professor in Operations Management at FORE School of Management. She is an electrical engineer from IIT-BHU, Varanasi and Masters in International Business from IIFT-New Delhi. She obtained her doctorate from Indian Institute of Management (IIM) Lucknow, making seminal contribution in the area of Spare Parts Management. She is a recipient of the coveted N.T.S.E. Scholarship. She has worked in the transportation and power industry for 16 years. She has published in International journals and participated in National and International Conferences. She brings the rich experience of the industry and tough academic rigor to her research. Her current areas of research include Service Operations, Operations Strategy, Product Service Systems, Humanitarian Supply Chain, Sustainability.

Kashi N. Singh is presently working as Professor in the Operations Management Area of the Indian Institute of Management, Lucknow. His areas of interest include: Operations Management, Supply Chain Management, Facility Location, and modeling of Production/Operations systems. Prof. Singh holds a Bachelor's degree in Mechanical Engineering from Patna University, and Master's and Doctoral degrees in Industrial Engineering \& Management from Indian Institute of Technology, Kanpur and Asian Institute of Technology, Bangkok, respectively. Prof. Singh, a full professor of more than twenty four years' standing, has about forty years of teaching and research experience to his credit. Currently he is a member of POMS, a life member of SOM, a Fellow of the Institution of Engineers (India), a member of the Institute for Operations Research and the Management Sciences (INFORMS) and the Manufacturing \& Service Operations Management (M\&SOM) Society. 


\begin{tabular}{|c|c|c|c|c|c|c|c|c|c|c|c|}
\hline Description & Price & $\begin{array}{l}\text { Losses per } \\
\text { day }\end{array}$ & $\begin{array}{l}\text { Lead } \\
\text { Time }\end{array}$ & $\begin{array}{c}\text { Spare Asset } \\
\text { Value }\end{array}$ & S/K & Mean & S.D & CV & Sigma & OPT Value & Class \\
\hline Windshield & 15800000 & 5000000 & 2 & 10000000 & 0.63 & 0.1 & 0.32 & 3.20 & 1.10 & 0.19 & $\mathrm{LcHv}$ \\
\hline Flap & 9552000 & 5000000 & 2 & 10000000 & 1.05 & 0.25 & 0.62 & 2.48 & 0.99 & 0.35 & $\mathrm{HcHv}$ \\
\hline Evacuation Slide & 4324000 & 5000000 & 2 & 10000000 & 2.31 & 0.1 & 0.32 & 3.20 & 1.10 & 1.1 & $\mathrm{HCHv}$ \\
\hline Antenna & 6800000 & 5000000 & 3 & 15000000 & 2.21 & 0.2 & 0.42 & 2.10 & 0.92 & 0.98 & $\mathrm{HcHv}$ \\
\hline Tank Unit & 4765000 & 5000000 & 2 & 10000000 & 2.10 & 0.2 & 0.42 & 2.10 & 0.92 & 0.91 & $\mathrm{HcHv}$ \\
\hline Piston & 8000000 & 5000000 & 3 & 15000000 & 1.88 & 0.2 & 0.42 & 2.10 & 0.92 & 0.77 & $\mathrm{HcHv}$ \\
\hline Gear Indicator Bulb & 5000 & 5000000 & 1 & 5000000 & 1000.00 & 0.1 & 0.32 & 3.20 & 1.10 & 739.91 & $\mathrm{HcHv}$ \\
\hline Fire Extinguisher & 75000 & 5000000 & 1 & 5000000 & 66.67 & 0.167 & 0.577 & 3.46 & 1.13 & 48.49 & $\mathrm{HcHV}$ \\
\hline Motor & 8100000 & 5000000 & 2 & 10000000 & 1.23 & 0.3 & 0.48 & 1.60 & 0.80 & 0.35 & HcLV \\
\hline Wheel Hub & 7300000 & 5000000 & 2 & 10000000 & 1.37 & 0.333 & 0.49 & 1.47 & 0.76 & 0.41 & HcLV \\
\hline Sensor & 10600000 & 5000000 & 1 & 5000000 & 0.47 & 0.4 & 0.52 & 1.30 & 0.70 & 0.03 & HcLv \\
\hline Cabin Pressure Amplifier & 50000 & 5000000 & 1 & 5000000 & 100.00 & 0.4 & 0.52 & 1.30 & 0.70 & 73.18 & HcLV \\
\hline Landing and Taxing Lights & 5000 & 5000000 & 1 & 5000000 & 1000.00 & 0.7 & 0.48 & 0.69 & 0.44 & 739.91 & HcLV \\
\hline Load Control Thermostat & 200000 & 5000000 & 2 & 10000000 & 50.00 & 0.3 & 0.48 & 1.60 & 0.80 & 110.22 & HcLV \\
\hline Cock pit lights & 2000 & 5000000 & 1 & 5000000 & 2500.00 & 0.7 & 0.48 & 0.69 & 0.44 & 1851 & HcLV \\
\hline Windshield defogger & 700000 & 5000000 & 2 & 10000000 & 14.29 & 0.7 & 0.48 & 0.69 & 0.44 & 9.68 & HcLV \\
\hline Compass & 500000 & 5000000 & 2 & 10000000 & 20.00 & 0.4 & 0.52 & 1.30 & 0.70 & 13.91 & HcLV \\
\hline
\end{tabular}

\begin{tabular}{|c|c|c|c|c|c|c|c|c|c|c|c|}
\hline Description & Price & $\begin{array}{l}\text { Losses per } \\
\text { day }\end{array}$ & $\begin{array}{l}\text { Lead } \\
\text { Time }\end{array}$ & $\begin{array}{l}\text { Spare Asset } \\
\text { Value }\end{array}$ & $\mathrm{S} / \mathrm{K}$ & Mean & S.D. & CV & Sigma & $\begin{array}{l}\text { OPT } \\
\text { Value }\end{array}$ & Class \\
\hline Latch Assy. & 33480 & 10000 & 2 & 20000 & 0.60 & 0.333 & 0.49 & 1.47 & 0.76 & 0.08 & LCLV \\
\hline Seat & 200000 & 31500 & 2 & 63000 & 0.32 & 0.3 & 0.48 & 1.60 & 0.80 & 0.02 & LCLV \\
\hline Tray table & 10000 & 20000 & 1 & 20000 & 2.00 & 0.7 & 0.48 & 0.69 & 0.44 & 0.65 & LCLV \\
\hline Head Phones & 2000 & 3000 & 1 & 3000 & 1.50 & 0.7 & 0.48 & 0.69 & 0.44 & 0.33 & LCLV \\
\hline Cabin Reading Lights & 1000 & 1000 & 1 & 1000 & 1.00 & 0.7 & 0.48 & 0.69 & 0.44 & 0.07 & LCLV \\
\hline Trolley Lock & 50000 & 10000 & 2 & 20000 & 0.40 & 0.4 & 0.52 & 1.30 & 0.70 & 0 & LCLV \\
\hline Galley Plug & 4000 & 4000 & 1 & 4000 & 1.00 & 0.3 & 0.48 & 1.60 & 0.80 & 0.24 & LCLV \\
\hline Individual Oxygen Supply & 50000 & 31500 & 0.5 & 15750 & 0.32 & 0.3 & 0.480 & 1.60 & 0.80 & 0.06 & $\mathrm{LcHv}$ \\
\hline Cockpit Voice Recorder & 1000000 & 20000 & 2 & 40000 & 0.04 & 0.1 & 0.32 & 3.20 & 1.10 & 0 & $\mathrm{LcHv}$ \\
\hline Data Flight Recorder & 1500000 & 20000 & 2 & 40000 & 0.03 & 0.1 & 0.32 & 3.20 & 1.10 & 0 & $\mathrm{LcHv}$ \\
\hline Stretcher & 1800000 & 10000 & 2 & 20000 & 0.01 & 0.08 & 0.29 & 3.63 & 1.15 & 0 & $\mathrm{LcHv}$ \\
\hline Crew Oxygen Mask & 50000 & 1000 & 2 & 2000 & 0.04 & 0.2 & 0.42 & 2.10 & 0.92 & 0 & $\mathrm{LcHv}$ \\
\hline Crew Rest Module & 75000 & 1000 & 2 & 2000 & 0.03 & 0.25 & 0.62 & 2.48 & 0.99 & 0 & $\mathrm{LcHv}$ \\
\hline Galley Water Faucet & 75000 & 1500 & 2 & 3000 & 0.04 & 0.2 & 0.42 & 2.10 & 0.92 & 0 & $\mathrm{LcHv}$ \\
\hline Arm cap & 100000 & 31500 & 1 & 31500 & 0.32 & 0.333 & 0.89 & 2.67 & 1.02 & 0.05 & $\mathrm{LcHv}$ \\
\hline Crew Seat & 250000 & 1000 & 2 & 2000 & 0.01 & 0.1 & 0.32 & 3.20 & 1.10 & 0 & $\mathrm{LcHv}$ \\
\hline
\end{tabular}

